\title{
Fruit and Vegetable Effect Changes in Blood Sugar Levels and Food Glycemic Index
}

\author{
Gurid Pramintarto Eko Mulyo*(D), Zidnie Silmi Kaffah, Mira Mutiyani, Angreni Ayuhastuti \\ Department of Nutrition, Poltekkes Kemenkes Bandung, Bandung, Indonesia
}

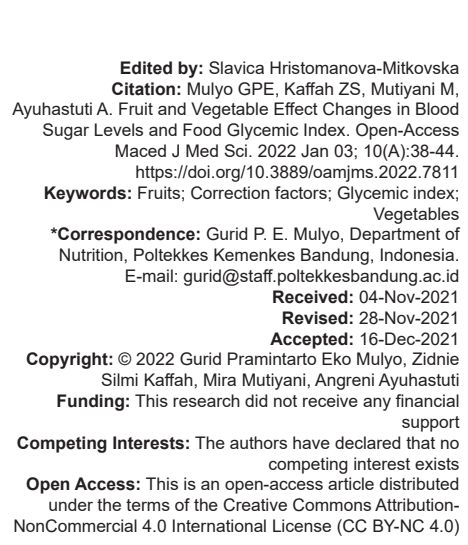

Introduction

Diabetes mellitus (DM) is a metabolic disease characterized by hyperglycemia. Hyperglycemia occurs due to defects in insulin secretion, decreased insulin action, or both. It will increase the concentration of glucose in the blood (hyperglycemia) [1]. According to Basic Health Research (Riskesdas) data in 2007 and 2013, the number of people with DM has almost doubled [2], [3].

The increasing prevalence of DM sufferers is closely related to changes in people's consumption patterns, including high sugar consumption and low fiber consumption. Based on research conducted by Hairani (2013) on the analysis of the trend of sugar imports in Indonesia, from 1997 to 2011, imports of raw sugar increased by 4.5 times [4]. In addition, based on research conducted by Imanuel (2013), which analyzes eating habits in the community, it is stated that $70 \%$ of people eat vegetables less than 3 times/day, and $64.4 \%$ of people do not consume fruit per day [5].

Fiber has a hypoglycemic effect because it can slow gastric emptying, glucose diffusion, and glucose absorption to reduce the increase in blood glucose [6].
There are two groups of food sources of fiber, namely, fruits and vegetables. Fruits tend to have a varying $\mathrm{GI}$ and fiber content. Watermelon (Citrullus vulgaris) contains low fiber, namely, $0.5 \mathrm{~g} / 100 \mathrm{~g}$ of fruit and a Gl included in the high class of 72 [7], [8]. So far, watermelon is often avoided by people with diabetes because of its sweet taste and high Gl; however, the glycemic load figure, which is $4 / 120 \mathrm{~g}$, is categorized as low [8].

Avocado (Persea americana) contains $1.4 \mathrm{~g}$ of fiber per $100 \mathrm{~g}$ of fruit and a $\mathrm{Gl}$ of 15 , classified in the low category [7]. Several studies have proven that avocados can reduce blood sugar levels, such as research conducted by Annisa Yuniarti in 2012 on the Effect of Giving Avocado Juice on Blood Sugar Levels in Type II DM Patients [9].

Vegetables tend to have a low GI and glycemic load and are high in fiber. Beans and carrots are examples of vegetables with high fiber content, which are $1.9 \mathrm{~g} / 100 \mathrm{~g}$ beans and $1 \mathrm{~g} / 100 \mathrm{~g}$ carrots [10]. Carrots (Daucus carota L.) have a Gl of 16 , and beans (Phaseolus vulgaris L.) have a $\mathrm{Gl}$ of 15 [8]. Based on research conducted by Ivo Gustiara in 2012, beans and carrots are one type of vegetable often consumed by teenagers [11].

So far, the list of GI and glycemic load of food has become a guideline for people with DM in choosing the type of food consumed to control blood sugar levels. 
The purpose of this study was to determine the effect of giving fruit (watermelon and avocado) and vegetables (beans and carrots) to blood sugar levels and the correction factor for changes in blood sugar levels and the $\mathrm{GI}$ of food.

\section{Method}

\section{Design and time}

The research design used in this study was a quasi-experimental two-group pre- and post-test to determine the effect of giving fruit (avocado and watermelon) and vegetables (beans and carrots) to changes in blood sugar levels. This research was conducted at Poltekkes Bandung, Department of Nutrition. The study started preparing the proposal until the data collection was carried out from August 2018 to March 2019. The sample was selected by purposive sampling with inclusion and exclusion criteria. The minimum sample size required is four people for each treatment group [12].

\section{Criteria and distribution of sample groups}

Inclusion criteria in this study were aged 18-21 years, did not suffer from DM, had no history of DM, blood glucose levels $2 \mathrm{~h}$ after eating 80-144 mg/ $\mathrm{dl}$, normal nutritional status (body mass index [BMI] 18.5-25.0), and willing to be a research sample by filling out a statement letter. While the exclusion criteria for this study were suffering from heart failure, kidney disease, stroke, ulcers, and other comorbidities, not being able to fast $10 \mathrm{~h}$ before the study and not being able to finish the intervention food provided by the researcher.

The sample was divided into two groups, namely, the fruit group and the vegetable group. The study was conducted for 6 days of data collection where between days were spaced 1 week. On the $1^{\text {st }}$ day of the study, interviews were conducted regarding personal data. The $2^{\text {nd }}$ day was given a standard bread intervention with the same calories as bread and fruit or vegetables. On the $3^{\text {rd }}$ day, $100 \mathrm{~g}$ of beans/avocado were given and on the $4^{\text {th }}$ day were given $100 \mathrm{~g}$ of bread with beans/avocado. On the $5^{\text {th }}$ day, $100 \mathrm{~g}$ of carrots/watermelon were given and on the $6^{\text {th }}$ day were given bread with carrots/watermelon as much as $100 \mathrm{~g}$.

\section{Intervention food}

The bread used was peeled white bread and then weighted according to the same calories as the bread and vegetable/fruit intervention. Standard bread of avocado intervention weighed $122 \mathrm{~g}$, while it was weighed $100 \mathrm{~g}$ for other interventions. Avocado and watermelon were cut and then weighed $100 \mathrm{~g}$ each. While vegetables, beans, and carrots are considered $100 \mathrm{~g}$ and then steamed. Bread for bread intervention with vegetables/fruits was weighed $88 \mathrm{~g}$.

\section{Blood drawing and blood glucose check}

The sample finger was cleaned using an alcohol swab and then allowed to dry. After that, the blood was taken with a soft click pen. The blood is inserted into the test strip bearing until it is filled. Wait for the examination process; the results of blood sugar levels will appear on the screen. The blood taken is peripheral blood as much as 0.2 micro mill. Blood sampling was performed 6 times: Fasting blood glucose, $0 \mathrm{~min}, 30 \mathrm{~min}, 60 \mathrm{~min}, 90 \mathrm{~min}$, and $120 \mathrm{~min}$ after the intervention. For the examination of GDP levels, the sample was previously fasted $10 \mathrm{~h}$ before measuring blood sugar.

\section{Data types and analysis}

The types of data collected are data on sample characteristics including age and gender, BMI, and blood sugar levels of GDP (fasting blood sugar), 0', 30', 60', 90', and 120' after the intervention. Age and gender data obtained using interviews; BMI data obtained by weighing and measuring weight using a scale with an accuracy of $0.1 \mathrm{~kg}$ and height using a microtia with an accuracy of $0.1 \mathrm{~cm}$; and data on blood sugar levels obtained by measuring using a glucometer. Gender data are categorized into male and female.

The statistical test used the t-independent test to determine the two differences in average age and BMI between the two study groups for normally distributed data. In contrast, for data that were not normally distributed, the Mann-Whitney U-test was performed. The ANOVA test was conducted to determine the difference between changes in blood sugar levels at $0,30,60,90$, and $120 \mathrm{~min}$ after the intervention for normally distributed data. The KruskalWallis test was performed for data that were not normally distributed. If there is a significant difference $(p<0.05)$ in the ANOVA test, it will be continued with the post hoc test.

\section{Results}

The results of this study were processed univariate and bivariate. Univariate for sample characteristics based on gender is shown in Table 1. 
Table 1: Characteristics of samples based on gender

\begin{tabular}{llllll}
\hline Gender & \multicolumn{2}{l}{ Vegetable group } & & & Fruit group \\
\cline { 2 - 3 } & $\mathrm{n}$ & 0 & & $\mathrm{n}$ & $\%$ \\
\hline Man & 0 & 0 & & 0 & 0 \\
Woman & 6 & 100 & & 7 & 100 \\
Total & 6 & 100 & 7 & 100 \\
\hline
\end{tabular}

The number of samples in this study was 14 people. Still, one person dropped out during the research process because it was discovered that the sample did not meet one of the exclusion criteria. All samples $(100 \%)$ are female and are students of the Bandung Health Polytechnic Department of Nutrition. The age of the sample ranged from 18 to 21 years. About $16.7 \%$ of the sample was 18 years old in the vegetable group, and $83.8 \%$ were 21 . While in the fruit group, $57.1 \%$ of the sample was 19 years old, $14.3 \%$ of the sample was 20 years old, and $28.6 \%$ was 21 years old. The characteristics of the sample based on age are shown in Table 2. There was no difference between age and BMI in the vegetable and fruit group based on statistical tests.

Table 2: Characteristics of samples based on age

\begin{tabular}{|c|c|c|c|c|c|c|}
\hline \multirow[t]{3}{*}{ Age } & \multicolumn{6}{|c|}{ Group } \\
\hline & \multicolumn{3}{|c|}{ Vegetable } & \multicolumn{3}{|c|}{ Fruit } \\
\hline & $\mathrm{n}$ & $\%$ & Mean \pm SD & $\mathrm{n}$ & $\%$ & Mean \pm SD \\
\hline 18 & 1 & 16.7 & $20.5 \pm 1.22$ & 0 & 0 & $18.71 \pm 0.95$ \\
\hline 19 & 0 & 0 & & 4 & 57.1 & \\
\hline 20 & 0 & 0 & & 1 & 14.3 & \\
\hline 21 & 5 & 83.3 & & 2 & 28.6 & \\
\hline
\end{tabular}

In Figure 1, changes in blood sugar levels can be seen in the intervention of avocado, watermelon, beans, and carrots. Based on the graph, it can be seen that avocado has the lowest graph of changes in blood sugar levels among the other three interventions. At the same time, the carrot chart is the highest. Based on changes in blood sugar levels, the highest graph increase was found in the watermelon intervention in the 0-30 min range (up $9.86 \mathrm{mg} / \mathrm{dl}$ ). In comparison, the highest decrease in blood sugar levels was found in the watermelon intervention in the 30-60 min range (down $11.29 \mathrm{mg} / \mathrm{dl}$ ). Changes in the blood sugar levels of the sample are shown in Table 3.

Table 4 shows the statistical tests on the intervention of beans, carrots, avocados, and watermelons. Based on the results of statistical tests, there were significant differences between changes in blood sugar levels of beans, carrots, avocados, and watermelons at 30,60 , and 90 min after the intervention with $p<0.05$. In the data carried out by the post hoc test, the results showed that there was a significant difference at 30 min between changes in blood sugar

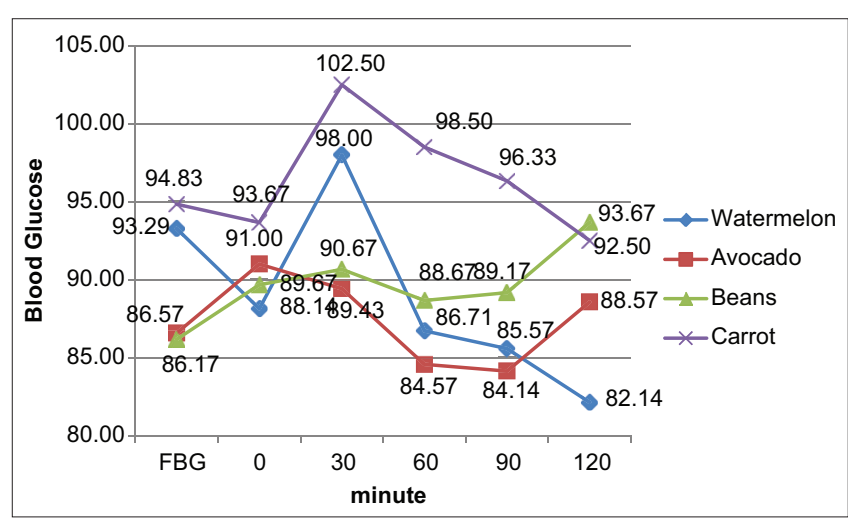

Figure 1: Changes in blood sugar levels in vegetable and fruit interventions

levels of the avocado and watermelon intervention. In addition, there is a significant difference at 60 and 90 min between changes in blood sugar levels the intervention sugar content of avocado and carrot and watermelon and carrot. The results of the post hoc test are shown in Table 5.

Table 4: Analysis of blood sugar levels in the vegetable and fruit group

\begin{tabular}{llllll}
\hline Intervention minutes & Mean & Min & Max & SD & $\mathrm{p}^{*}$ \\
\hline FBG & 90.19 & 77 & 110 & \pm 7.69 & 0.079 \\
PP0 & 90.54 & 79 & 121 & \pm 8.90 & 0.259 \\
PP30 & 95.04 & 81 & 113 & \pm 7.75 & $0.002^{*}$ \\
PP60 & 89.31 & 74 & 108 & \pm 7.88 & $0.003^{*}$ \\
PP90 & 88.5 & 70 & 103 & \pm 7.09 & $0.004^{*}$ \\
PP120 & 88.92 & 71 & 105 & \pm 8.70 & 0.059 \\
\hline${ }^{*}$ ANOVA. $P<0.05$ (there is a significant difference), FBG: Fasting blood glucose. &
\end{tabular}

In Figure 2, changes in blood sugar levels can be seen in the intervention of standard bread with fruit or vegetables. Based on the graph, it can be seen that the four intervention charts for bread with vegetables or fruit are below the standard bread chart. In the range of minutes $0-60 \mathrm{~min}$, the graph of changes in blood sugar levels of beans is the lowest among other interventions, while in the field of minutes $90-120 \mathrm{~min}$, the graph of bread and avocado intervention is the lowest.

Table 5: Post hoc test results of blood sugar levels in the vegetable and fruit group intervention

\begin{tabular}{lllll}
\hline Time & Type of intervention & Beans & Carrot & Watermelon \\
\hline $300^{\prime}$ & Avocado & 0.968 & 0.052 & $0.020^{*}$ \\
& Watermelon & 0.076 & 0.682 & \\
& Beans & & 0.084 & \\
60 & Avocado & 1 & $0.003^{*}$ & 1 \\
& Watermelon & 1 & $0.014^{*}$ & \\
& Beans & & 0.101 & \\
& Bo' & 0.731 & $0.005^{*}$ & 1 \\
& Avocado & 1 & $0.014^{*}$ & \\
& Watermelon & & 0.15 & \\
& Beans & &
\end{tabular}

Table 3: Changes in blood sugar levels in each intervention

\begin{tabular}{|c|c|c|c|c|c|c|}
\hline \multirow[t]{2}{*}{ Intervention } & \multirow[t]{2}{*}{ FBG $\pm S D$ (fasting blood glucose) } & \multicolumn{5}{|l|}{ Minutes } \\
\hline & & $0 \pm S D$ & $30 \pm S D$ & $60 \pm S D$ & $90 \pm S D$ & $120 \pm S D$ \\
\hline Beans & $86.17 \pm 7.70$ & $89.67 \pm 8.91$ & $90.67 \pm 5.04$ & $88.67 \pm 4.68$ & $89.17 \pm 3.54$ & $93.67 \pm 4.46$ \\
\hline Bread with beans & $91.5 \pm 1.38$ & $108.5 \pm 14.19$ & $122.83 \pm 24.93$ & $116.17 \pm 9.06$ & $117 \pm 14.67$ & $111 \pm 9.27$ \\
\hline Carrot & $94.83 \pm 10.98$ & $93.67 \pm 7.34$ & $102.5 \pm 8.87$ & $98.5 \pm 7.64$ & $96.33 \pm 6.31$ & $92.5 \pm 12.01$ \\
\hline Bread with carrot & $89 \pm 10.55$ & $106.67 \pm 25.80$ & $134.67 \pm 21.89$ & $124 \pm 14.32$ & $109.5 \pm 21.88$ & $110.17 \pm 17.43$ \\
\hline Avocado & $86.57 \pm 4.50$ & $91 \pm 13.27$ & $89.43 \pm 4.83$ & $84.57 \pm 7.66$ & $84.14 \pm 7.40$ & $88.57 \pm 3.95$ \\
\hline Bread with avocado & $86.57 \pm 6.92$ & $100.29 \pm 11.77$ & $128.86 \pm 6.47$ & $121.14 \pm 5.43$ & $109.14 \pm 4.02$ & $111.57 \pm 6.50$ \\
\hline Watermelon & $93.29 \pm 3.45$ & $88.14 \pm 5.08$ & $98 \pm 4.28$ & $86.71 \pm 3.78$ & $85.57 \pm 4.11$ & $82.14 \pm 8.61$ \\
\hline Bread with watermelon & $85.86 \pm 8.17$ & $97.14 \pm 9.87$ & $130.57 \pm 14.60$ & $127.57 \pm 18.32$ & $124 \pm 15.77$ & $110.29 \pm 14.41$ \\
\hline
\end{tabular}




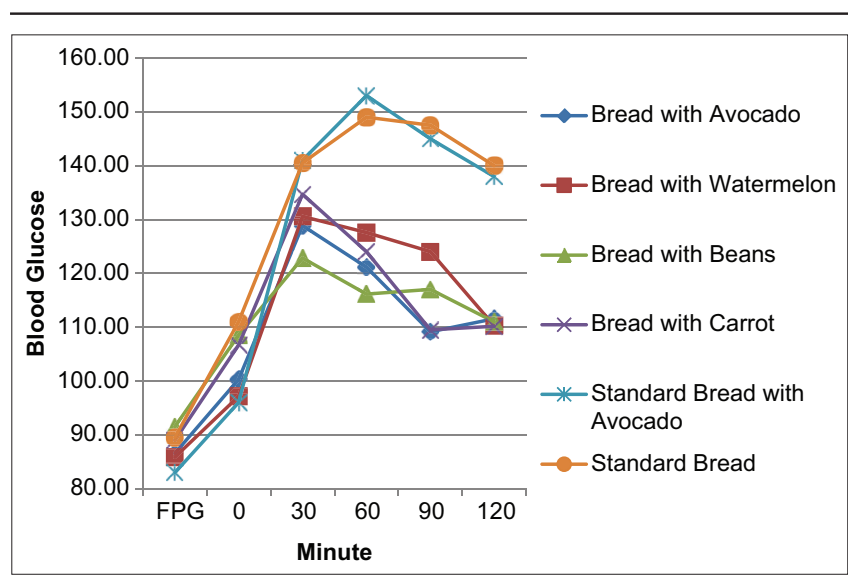

Figure 2: Changes in blood sugar levels intervention bread with vegetables or fruits

The most significant change in the increase in blood sugar levels was found in the $30^{\text {th }}$ min bread and watermelon intervention (up $33.43 \mathrm{mg} / \mathrm{dl}$ ), and the highest decrease was found in the $90^{\text {th }}$ min standard bread intervention (down $18.89 \mathrm{mg} / \mathrm{dl}$ ) then followed by the provision of bread and carrots intervention at the $90^{\text {th }} \min$ (down $14.50 \mathrm{mg} / \mathrm{dl}$ ).

In Table 6, it can be seen the results of statistical tests on the comparison of blood sugar levels in the intervention of standard bread with bread and beans, bread and carrots, bread and avocado, and bread and watermelon. Based on the results of statistical tests, there was a significant difference between changes in blood sugar levels in the intervention group of beans, avocado, and watermelon at $30 \mathrm{~min}$ after the intervention. At the same time, the new carrot intervention was meaningful at the $60^{\text {th }} \mathrm{min}$.

Table 6: Comparative analysis of blood sugar levels between bread and vegetable or fruit groups with standard bread

\begin{tabular}{lll}
\hline Time & Intervention & p-value \\
\hline $300^{\prime}$ & Beans & $0.046^{* *}$ \\
& Carrot & 0.07 \\
& Avocado & $0.008^{* *}$ \\
& Watermelon & $0.002^{* *}$ \\
& Beans & $0.000^{*}$ \\
& Carrot & $0.001^{*}$ \\
& Avocado & $0.000^{*}$ \\
& Watermelon & $0.000^{*}$ \\
$900^{\prime}$ & Beans & $0.000^{*}$ \\
& Carrot & $0.003^{*}$ \\
& Avocado & $0.003^{* *}$ \\
& Watermelon & $0.003^{* *}$ \\
$120{ }^{\prime}$ & Beans & $0.010^{* *}$ \\
& Carrot & $0.002^{*}$ \\
& Avocado & $0.000^{*}$ \\
& Watermelon & $0.000^{*}$ \\
\hline${ }^{*}$ ANOVA, ${ }^{* *}$ Kruskal-Wallis. $P<0.05$ (there is a significant difference). &
\end{tabular}

In the data carried out by the post hoc test, the results showed a significant difference in changes in blood sugar levels of standard bread and white bread with avocado starting $30 \mathrm{~min}$ after the intervention. Standard bread and bread with beans showed a significant difference at 60 min after the intervention.

Standard bread and bread with carrots showed a significant difference at 90 min after the intervention. Standard bread and bread with watermelon showed a significant difference at 120 min after the intervention.

The results of the post hoc test are shown in Table 7. Meanwhile, there were no statistically significant differences in comparing blood sugar levels of bread and beans, bread and carrots, bread and avocado, and bread and mango.

Table 7: Post hoc test results comparison of blood sugar levels between bread and vegetable or fruit groups with standard bread

\begin{tabular}{|c|c|c|c|c|c|c|}
\hline \multirow[t]{2}{*}{ Time } & \multirow[t]{2}{*}{ Intervention } & \multicolumn{4}{|c|}{ Standard bread } & \multirow[t]{2}{*}{$\mathrm{p}^{*}$} \\
\hline & & Mean & Min & Max & SD & \\
\hline $30^{\prime}$ & Bread with avocado & 132.2 & 120 & 120 & \pm 7.54 & $0.015^{\star *}$ \\
\hline \multirow[t]{2}{*}{$60^{\prime}$} & Bread with avocado & 130.4 & 112 & 152 & \pm 15.55 & $0.000^{* *}$ \\
\hline & Bread with beans & 124.11 & 104 & 140 & \pm 13.90 & $0.045^{*}$ \\
\hline \multirow[t]{3}{*}{ 90' } & Bread with avocado & 119.6 & 104 & 144 & \pm 17.15 & $0.000^{\star *}$ \\
\hline & Bread with beans & 126.17 & 94 & 144 & \pm 17.99 & $0.022^{\star *}$ \\
\hline & Bread with carrot & 121.17 & 84 & 144 & \pm 24.61 & $0.040^{* *}$ \\
\hline \multirow[t]{3}{*}{$120^{\prime}$} & Bread with avocado & 119.2 & 101 & 137 & \pm 13.38 & $0.000^{* *}$ \\
\hline & Bread with beans & 119.72 & 93 & 137 & \pm 14.99 & $0.004^{\star *}$ \\
\hline & Bread with watermelon & 118.35 & 94 & 137 & \pm 17.52 & $0.010^{\star *}$ \\
\hline
\end{tabular}

Table 8 shows that food's $\mathrm{Gl}$ is obtained based on the area under the curve calculated using the trapezoid calculation. After being averaged from each sample, the final results of the GI of each test food are shown in Table 8. Based on the table, it can be seen that the highest $\mathrm{GI}$ is the bread and watermelon (88.90\%), and the lowest is among the intervention foods (excluding bread) are the bread and avocado (84.26\%).

Table 8: Glycemic index of intervention food

\begin{tabular}{lll}
\hline Intervention & Area & Glycemic index \\
\hline Bread with avocado & $13.953,60$ & 84.26 \\
Bread with beans & $13.972,50$ & 85.22 \\
Bread with carrot & $14.297,30$ & 87.2 \\
Bread with watermelon & $14.575,70$ & 88.9 \\
Standard bread with vegetables and watermelon & $16.395,00$ & 100 \\
Standard bread with avocado & $16.560,00$ & 100 \\
\hline
\end{tabular}

Table 9 shows that the correction factor was calculated comparing the difference in changes in blood sugar levels of the intervention with blood sugar levels, which had the same calories as the intervention food. The average change in blood sugar levels from each intervention is shown in Table 9. The correction factor can describe the ability of the intervention material (beans, carrots, watermelon, and avocado) to prevent an increase in blood sugar levels when consumed together with other foods. Table 9 shows that avocado has the highest correction factor while watermelon has the lowest correction factor.

Table 9: Correction factors for average changes in blood sugar levels

\begin{tabular}{lllllll}
\hline Intervention & 0 & 30 & 60 & 90 & 120 & Mean \\
\hline Bread with beans & -7.43 & 10.99 & 19.89 & 19.03 & 18.98 & 12.29 \\
Bread with carrot & -5.61 & 2.42 & 14.48 & 24.22 & 19.59 & 11.02 \\
Bread with avocado & -5.56 & 7.96 & 20.30 & 24.21 & 18.56 & 13.09 \\
Bread with watermelon & 3.82 & 5.38 & 12.02 & 14.19 & 19.50 & 10.98 \\
\hline
\end{tabular}

\section{Discussion}

Watermelon has the most significant $\mathrm{Gl}$ and the lowest fiber content among the other three $[7,8]$. It is supported by statistical test data on changes in watermelon blood levels; there is a significant difference starting at $30 \mathrm{~min}$ compared to other intervention groups. In Graph 2, overall, the highest increase in blood sugar levels is found in watermelon at minute 
30 , and the highest decrease is found in watermelon at minute 60 .

When comparing changes in blood sugar levels of standard bread with bread and beans, both have the same increase in GDP until the $30^{\text {th }} \mathrm{min}$, where the chart for standard bread has a higher increase in blood sugar levels (up $48.5 \mathrm{mg} / \mathrm{dl}$ ) than bread and beans (up $31.33 \mathrm{mg} / \mathrm{dl}$ ). The increase in blood sugar levels signals the body to produce insulin which plays a role in helping blood sugar enter the cells [13]. After the $30^{\text {th }} \mathrm{min}$, the bread and beans chart experienced a decline, while the standard bread chart only fell after the $60^{\text {th }} \mathrm{min}$. At that minute, the decrease in blood sugar levels showed that blood sugar had entered the cells [14]. At the $60^{\text {th }} \mathrm{min}$, there is a difference where the chart on the standard bread has decreased to the $120^{\text {th }} \mathrm{min}$.

Meanwhile, the bread and beans chart increased slightly in the $90^{\text {th }}$ min and fell again in the $120^{\text {th }} \mathrm{min}$. The fiber content in beans causes blood sugar to be digested gradually and has a longer absorption time [15]. In the range of 0-120 $\mathrm{min}$, the increase in blood sugar levels of bread and beans was not higher than standard bread. The fiber in beans can help lower blood sugar levels by absorbing water and binding glucose, reducing blood sugar availability. Fiber can help the absorption of glucose in the blood and slow the release of glucose in the blood [16].

Beans contain water-soluble fiber to slow down the absorption of glucose in the body [17]. In addition to the high fiber content compared to other vegetables (containing $1.9 \mathrm{~g}$ of fiber per $100 \mathrm{~g}$ of beans), beans have a low GI of 15 . Foods with a low GI will be slowly broken down and slowly absorbed into the bloodstream to help lower blood pressure and blood sugar levels [18]. In addition to the fiber content and $\mathrm{Gl}$, beans also contain flavonoid compounds that are important in preventing DM. Flavonoid compounds can act as antioxidants that function to protect pancreatic cells from free radical damage, can increase insulin sensitivity, and also serve as alfa-amylase ( $\alpha$-amylase) inhibitors [19]. Based on the results of statistical tests, there was a significant difference between changes in blood sugar levels of standard bread with bread and beans starting at $60 \mathrm{~min}$.

When comparing changes in blood sugar levels of standard bread with bread and carrots, both have the same increase in GDP until the $30^{\text {th }}$ minute, where the chart for standard bread has a higher increase in blood sugar levels (up $48.50 \mathrm{mg} / \mathrm{dl}$ ) than bread and carrots (increased by $45.67 \mathrm{mg} / \mathrm{dl}$ ). After the $30^{\text {th }} \mathrm{min}$, the bread and carrot chart experienced a decline, while the standard bread chart only fell after the $60^{\text {th }} \mathrm{min}$. In the $30^{\text {th }}$ to the $120^{\text {th }}$ min range, it can be seen that the increase in blood sugar levels of bread and carrots is not higher than that of standard bread; this is because the fiber contained in carrots has a mechanism to lower blood sugar levels [16]. In addition to fiber content, carrots also have a low $\mathrm{Gl}$ which both have a role in lowering blood sugar levels.
In addition to fiber and the $\mathrm{Gl}$ that can help control blood sugar levels, carrots also contain antioxidant compounds from non-enzymatic types, consisting of micronutrients in the form of vitamins. Some of the vitamins found in carrots function as antioxidants, including Vitamin $\mathrm{C}$ and beta-carotene. These antioxidants can help control blood sugar levels by protecting pancreatic beta-cells from free radical attack [20]. Based on the results of statistical tests, there was a significant difference between changes in blood sugar levels of standard bread with bread and carrots at $90 \mathrm{~min}$.

When comparing changes in blood sugar levels of standard bread with bread and avocado, there is no difference between changes in blood sugar levels of GDP until minute 0 . Both are the same up and not much different. The difference was seen after minute 0 , where the standard bread chart experienced a higher increase in blood sugar levels (up $45 \mathrm{mg} / \mathrm{dl}$ ) than bread and avocado (up $28.57 \mathrm{mg} / \mathrm{dl}$ ). Then, the bread and avocado chart dropped after the $30^{\text {th }} \mathrm{min}$ to the $90^{\text {th }} \mathrm{min}$, while the standard bread chart only dropped after the $60^{\text {th }} \mathrm{min}$. In the 0-120 min range, it can be seen that the increase in blood sugar levels of bread and avocado is not higher than that of standard bread; this is because the fiber contained in avocado can help lower blood sugar levels [16]. An adequate fiber diet causes complex carbohydrates and fiber so that the digestibility of carbohydrates is reduced. This situation can reduce the increase in blood sugar and keep it under control [15].

In addition to high fiber content, avocados also have a low $\mathrm{Gl}$ which both have a role in lowering blood sugar levels [21]. Avocados are fruits that have antidiabetic effects that can help the body compensate for disturbances in blood sugar in the body [14].

Avocados contain Vitamin E, which can help reduce the risk of damage to pancreatic cells due to excess reactive oxygen (ROS), thereby reducing the risk of hyperglycemia due to insufficient insulin or insulin resistance [22]. Based on the results of statistical tests, there was a significant difference between changes in blood sugar levels of standard bread with bread and avocado starting at $30 \mathrm{~min}$.

If you compare the blood sugar levels of standard bread with bread and watermelon, they both rise, and the increase is not much different. The bread and watermelon charts start to fall after the $30^{\text {th }} \mathrm{min}$, while the standard bread charts start to fall after the $60^{\text {th }}$ min. From minute 0 to minute 30 , there is not much difference between the graph of bread and watermelon with standard bread. Watermelon has a high Gl which causes food to be quickly broken down and quickly absorbed into the bloodstream. In the $90^{\text {th }}$ to the $120^{\text {th }}$ min range, it can be seen that the graph of blood sugar levels of bread and watermelon is not higher than standard bread; this is because the fiber contained in watermelon has a mechanism to lower blood sugar 
levels [16]. Although it has a high GI level and contains less fiber than other fruits, the fiber in watermelon can help lower blood sugar levels. The content contained in watermelon can stimulate insulin production, thereby lowering blood sugar levels [21].

According to Sutarya (2009), watermelon contains relatively higher lycopene than tomatoes, indicating the highest lycopene-producing fruit. Although watermelon is sweet, it has relatively low sugar. In addition, the benefits of watermelon for diabetics, namely, the content contained in watermelon, can stimulate insulin production, thereby lowering blood sugar levels [20]. Based on the results of statistical tests, there was a significant difference between changes in blood sugar levels of standard bread with bread and watermelon starting at $120 \mathrm{~min}$.

When comparing changes in blood sugar levels in the intervention of bread and beans, bread and carrots, bread and avocado, and bread and watermelon, both graphs and statistical test results, there was no significant difference between each intervention. However, bread and avocado have a lower $\mathrm{Gl}$ than other interventions when viewed based on the Gl. Foods with low and high Gl values can be distinguished based on the speed of digestion, glucose absorption, and fluctuating blood levels. Foods with low GI values will digest food slowly, so the rate of gastric emptying is slow. It causes the food suspension (chyme) to reach the small intestine more slowly so that glucose absorption in the small intestine becomes slow and fluctuations in blood glucose levels are relatively small. On the other hand, food with a high $\mathrm{Gl}$ value characterizes the rate of gastric emptying, carbohydrate digestion, and glucose absorption, which takes place rapidly so that fluctuations in blood glucose levels are also relatively high. It is because glucose absorption mainly occurs in the small intestine [21].

In addition, when viewed from the correction factor for blood sugar levels, the avocado intervention has the highest correction factor. The higher the correction factor, the higher the ability to prevent blood sugar levels and vice versa. It can be concluded that avocado can better avoid increasing blood sugar levels than the other three interventions. It means that avocados have a higher ability to prevent an increase in blood sugar levels among the four interventions. Based on research conducted by Srikayati Widyastuti and I Nyoman Suarsana in 2011, the highest blood sugar release occurred at $60 \mathrm{~min}$ after eating [6]. Table 9 shows that at $60 \mathrm{~min}$ after the intervention, the avocado lowered blood sugar levels the highest among the three other interventions.

Of the four interventions given, the watermelon fruit intervention has the lowest ability compared to other interventions. It is evidenced by the highest $\mathrm{GI}$ of bread and watermelon and the lowest correction factor for blood sugar levels. Watermelon contains lower fiber and the highest $\mathrm{Gl}$ compared to other interventions.
Avocados and beans have the same Gl and fiber content that is not much different [7]. If you look at the graph, it can be seen that avocados can lower blood sugar levels more than beans. It is related to the type of fiber they both have. Most fruits contain higher soluble fiber than vegetables [21].

Soluble fiber can absorb fluids and form a gel in the stomach. The gel slows the process of gastric emptying and absorption of nutrients. The gel can slow down the peristaltic motion of nutrients (glucose) from the small intestine wall to the absorption area, decreasing blood glucose levels [23]. The content of soluble fiber in vegetables is less when compared to fruit; vegetables contain more insoluble fiber [6].

Foods with high insoluble fiber content usually contain low calories, low sugar, and fat content, which can help reduce the occurrence of obesity and DM [16].

Although both fibers have the exact mechanism for lowering blood sugar levels, several previous studies, such as those conducted by Nadimin et al. in 2009, recommended the consumption of soluble fiber to help control blood sugar levels [24]. Based on research conducted by Nitta Isdiani and Dadang Rosmana in 2017 on the GI, glycemic load, and energy intake plays a role in controlling blood glucose levels in patients with Type 2 DM, suggesting consuming snacks in the form of fruits and meeting energy intake as needed [25]. Hence, it can be concluded that the fiber in fruit is more recommended to prevent an increase in blood sugar levels.

\section{Conclusion}

Giving vegetables and fruit affect changes in blood sugar levels. When compared with standard bread with the same calories as the intervention food (bread with fruit or vegetables), there was a significant difference in blood sugar levels of standard bread and bread with avocado starting 30 min after giving the intervention. Standard bread and bread with chickpeas showed a significant difference in changes in blood sugar levels starting $60 \mathrm{~min}$ after the intervention. Standard bread and bread with carrots showed a significant difference in blood sugar levels at 90 min after the intervention. Standard bread and bread with watermelon showed a significant difference in blood sugar levels at 120 min after the intervention.

Comparing changes in blood sugar levels of the intervention of bread and beans, bread and carrots, bread and avocado, and bread and watermelon, both graphic and statistical test results showed no significant difference. However, bread and avocado have a lower $\mathrm{Gl}$ than other interventions when viewed based on the $\mathrm{GI}$. In addition, when viewed from the correction factor for blood sugar levels, the avocado intervention has 
the highest correction factor. It can be concluded that avocado can better prevent increased blood sugar levels than the other three interventions.

When comparing avocados (fruit) and beans (vegetables) with the same GI content and have not much different fiber content, avocados can lower blood sugar levels more than beans. The more soluble fiber in fruit, the more recommended to help control blood sugar levels.

\section{References}

1. American Diabetes Association. Diagnosis and classification of diabetes mellitus. Diabetes Care. 2011;34 Suppl 1:S62-9. https://doi.org/10.2337/dc11-S062

PMid:21193628

2. Riskesdas. Indonesian RISKESDAS Basic Health Research Report 2007. Jakarta: Research and Development Agency of the Ministry of Health of the Republic of Indonesia; 2007.

3. Riskesdas. RISKESDAS Indonesia Basic Health Research Report. Jakarta: Research and Development Agency of the Ministry of Health of the Republic of Indonesia; 2013.

4. Hairani RI, Aji JM. Analysis of sugar production and import trends and factors affecting sugar imports. Berkara IImiah Pertanian. 2014;1:77-85.

5. Kant I, Pandelaki AJ, Lampus BS. An overview of the people's eating habits in the Allandrew Permai housing, Malalayang I village, Neighborhood XI, Manado city. JKedokteran Komunitas Tropik. 2013;1:88-95.

6. Gropper SS, Smith JL, Groff JL. Carbohydrates: Advanced Nutrition and Human Metabolism. 5th ed. Australia, Canada: Thomson Wadsworth; 2009. p. 69-77.

7. Indonesian Nutritionist Association (PERSAGI). Indonesian Food Composition Table. Jakarta: PT Elex Media Komputindo; 2009.

8. Atkinson FS, Foster-Powell K, Brand-Miller JC. International tables of glycemic index and glycemic load values: 2008. Diabetes Care. 2008;31(12):2281-3. https://doi.org/10.2337/ dc08-1239 PMid:18835944

9. Utami AY. The Effect of Avocado Juice on Blood Sugar Levels in Type II Diabetes Mellitus Patients in the Jetis II Public Health Center Bantul [Thesis]. Yogyakarta: Aisyiyah College of Health Sciences; 2012.

10. Rashid H, Bukhari A, Syauki Y. Clinical Skills Work Guidebook III Diet Management in Diabetes Mellitus and Obesity Patients.
Makassar: Faculty of Medicine, Hasanuddin University; 2017.

11. Gustira I. Consumption of vegetables and fruits in students of SMA Negeri 1 Pekanbaru. Vol. 1. In: North Sumatra: Journal of Precure. Epi Treat Unit-University of North Sumatra; 2012.

12. Study P, Doctor P, Medicine F, Science DAN, Negeri UI, Hidayatullah S. Effects of Insulin Leaf Extract (Smallanthus sonchifolia) on Blood Glucose Levels, Body Weight, and Triglyceride Levels in Sprague Dawley Strain Induced Diabetes Rats; 2014

13. Banjarnahor E, Wangko S. Pancreatic beta cells synthesis and secretion of insulin. J Biomed. 2012;4(3):156-62.

14. Khoirunnisa R. The Effect of Giving Processed Fruits on Blood Glucose Levels [Thesis]. Bandung: Poltekkes Bandung Department of Nutrition; 2018.

15. Santoso MP. Food fiber (dietary fiber) and its benefits. Magistra. 2011;75:35-40.

16. Astawan, M. The use of dietary fiber to prevent various diseases. J Food Sci Technol. 1998;3(2).

17. Sumardiono, Siswo, Basri, Mohamad P, Sihombing, Rony Analysis of Psycho-chemical Properties of Tomato Fruit (Lycopersicone culentum) Apple Tomato Type, to Increase the Functional Value of Tomato Fruit as a Local Food Commodity [Proceedings of the S1 Final Project Seminar]. Indonesia: Chemical Engineering Department, UNDIP; 2009.

18. Hoerudin. Fruit glycemic index and its implications in controlling blood glucose levels. Agric Postharvest Technol Bull. 2012;8:80-98.

19. Kurniawati D, Sutrisna EM, Wahyuni AS. Test for reducing blood glucose levels by $70 \%$ ethanol extract of beans leaves (Phaseolus vulgaris L.) in male rabbits loaded with glucose. $J$ Biomed. 2012;4(1):1-8.

20. Dharma S, Saputra H, Suharti N. Effect of carrot juice (Daucus carota, Linn) on blood glucose levels of female white mice. Higea Pharm J. 2011;3(1):31-5.

21. Abdullah, Budiyanto A, Hoerudin. Glycemic Index Value of Food Products and Factors Affecting It. Bogor: Journal of Agricultural Postharvest Research and Development; 2013.

22. Dasgupta A, Klein K. Antioxidants in Food, Vitamins, and Supplements. USA: Elsevier; 2014. p. 153-62.

23. Gate SF. Soluble Fiber Amounts in Fruits and Vegetables; 2015. Available from: https://www.healthyeating.sfgate.com/solublefiber-amounts-fruits-vegetables-4408.html [Last accessed on 2018 Sep 23].

24. Nadimin, Ayu SD, Sadariah. The Effect of High-Fibre Diet DM on Reduction in Blood Sugar Levels in Type-2 Diabetes Mellitus Patients At Salewangang Hospital, Kab. 1st ed., Vol. 7. Maros: Food Nutrition Media; 2009.

25. Isdiany N, Rosmana D. Glycemic index, glycemic load, and energy intake play a role in controlling blood glucose levels in Type 2 DM patients. J Health Res. 2017;7(1):17-24. Available from: https://www.juriskes.com/ojs/index.php/jrk/article/view/26 [Last accessed on 2019 May 23]. 